\title{
Mário Rigatto, meu Mestre (28/12/1928 - 17/1/2000)
}

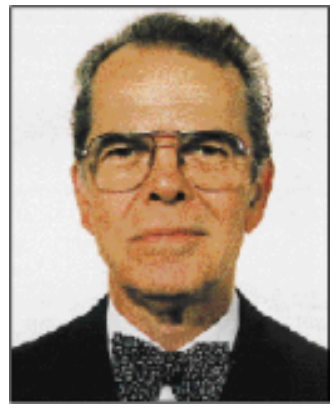

Dr. Mário Rigatto
Insuperável desafio traçar o perfil de Mário Rigatto em algumas linhas, tal a multiplicidade de seus dons. Mário Rigatto foi um prodígio da natureza e representa a mais completa vocação para o ensino e a pesquisa que conheço. Em 1960, nos encontramos pela primeira vez na nossa saudosa Enf. 29 da Santa Casa de Misericórdia de Porto Alegre, Rigatto recém retornado de um estágio de três anos em cardiopneumologia nos EUA e eu terceiranista de Medicina, ingressando na atividade hospitalar. Logo constatei estar ao lado de alguém ímpar. Alguns anos antes, o Prof. Rubens Maciel, então chefe do Serviço, o havia "descoberto" como um aluno promissor. Naquele momento, "descobri-o" como um Mestre já formado. Fomos amigos fraternais por 40 anos e trabalhamos juntos por 25 anos.

Nascido em Porto Alegre, em 28/12/1928, segundo dos quatro filhos de Arthur e Anna Luiza Rigatto, cedo mostrou seus talentos como estudante e orador. Primeiros lugares na vida do Rigatto foram uma constante. Médico da Enf. 29 da Santa Casa de Porto Alegre, desde sua formatura, em 1954, em 1957 seguiu para um estágio de três anos nos Estados Unidos, nas Universidades de Cornell e de Columbia, New York, nesta sob a preceptoria de Alfred Fishman, tendo produzido trabalhos de pesquisa que mereceram publicação nos melhores periódicos daquele país. Buscando as ferramentas que lhe permitiam a perfeita interpretação da produção científica, em 1961 e 1962 realizou o Curso de Estatística Aplicada às Ciências Médicas, na Faculdade de Higiene de São Paulo. Tão bem estudou e aprendeu essa ciência que a transmitiu magistralmente a centenas de alunos, chegando a eclipsar os profissionais do assunto. De todos os cursos que participou, sempre espalhou os conhecimentos adquiridos, nunca encapsulando-os só para si.

Amador é alguém que não conseguiu chegar a profissional. Sua carreira de pesquisador, de longe a mais profícua do nosso meio, iniciou-se formalmente em 1960, com dedicação em tempo integral à vida universitária, o primeiro da Faculdade de Medicina da UFRGS no ciclo clínico, através da montagem e funcionamento do Laboratório Cardiopulmonar da Santa Casa de Porto Alegre, patrocinado pela Fundação Rockfeller. Ainda recordo com muito carinho, quando, sábados à tarde, desencaixotávamos o material com a curiosidade e a interrogação de aonde iria levar-nos. Em 1966, foi recebido na Universidade de Londres como Professor visitante e pesquisador. Também nas Universidades de Oxford, Cambridge, Edimburgo, Estocolmo e Goteburg. Não sou dos que pensam que quanto mais longe melhor ou mais importante. Tenho visto muito trabalho escrito em português mais rico em con- teúdo que outros de menor qualidade mas mais valorizados só porque escritos em inglês. O santo para ser bom tem que fazer milagre na própria casa, ou seja, melhorar seu meio. E Rigatto fez isso ao longo de sua vida. Suas idéias foram fatores de peso nos rumos da pesquisa no nosso país, com diversos cargos na FAPERGS, desde 1964. A partir de 1969, Pesquisador-Conferencista e Pesquisador IA do então Conselho Nacional de Pesquisas (CNPq), entre outras atividades.

As linhas de pesquisa eleitas foram circulação pulmonar, doença pulmonar obstrutiva crônica, tabagismo, fisiopatologia do exercício físico, equilíbrio ácido-básico e envelhecimento. Em cada uma dessas foi sempre um campeão, deixando sua marca com contribuições originais, como são os casos da medida do tempo de recirculação pulmonar e do aperfeiçoamento da medida do débito cardíaco por técnica respiratória, incruenta. Também estudos sobre acompanhamento da descompensação cardíaca pelo gradiente alvéoloarterial de oxigênio, cor pulmonale crônico e fisiopatologia pulmonar. Síntese magnífica de sua visão sobre esses temas é o livro "Fisiopatologia da Circulação Pulmonar", não uma compilação de vários autores, mas pessoal e intransferível no estilo, editado em 1973, que, como as obras primas, se mantém sempre atual. Suas reflexões sobre corações acessórios, ainda não bem absorvidas, podem modificar conceitos arraigados sobre a circulação do sangue.

Foi um dos introdutores da Residência Médica no Sul do Brasil em 1960, um lutador em favor da qualificação do ensino médico. A organização, em 1971, e a coordenação de 1972 a 1978 do Curso de Mestrado em Pneumologia da UFRGS, o primeiro curso de Pós-Graduação implantado na região Sul do Brasil, e o mais fértil em teses, são serviços seus, sendo também Professor Responsável por cinco disciplinas nesse curso e de outras em outros cursos de pósgraduação. Além disso, Vice-Reitor da UFRGS, em 1981. Sua atuação no campo da educação médica o levou a grandes alturas nacionais e internacionais. No terreno das publicações foi insuperável: muitas centenas de trabalhos publicados no país e no exterior entre artigos médicos, resumos, teses feitas ou orientadas, dois livros, capítulos de livros, ensaios. No total, em congressos médicos nacionais ou internacionais, mais de duas mil comunicações de cunho científico ou médico-social, o que equivale provavelmente a maior média de palestras feita por alguém no Brasil. Livre-Docente em 1961, e Professor Titular de Medicina Interna em 1986, aprovado com média 10, naturalmente com o primeiro lugar.

Sua vida associativa também é extenuante: Inúmeras lideranças na AMRIGS, Presidente da Sociedade de Cardiologia do Rio Grande do Sul, membro das Academia Sul-RioGrandense e Nacional de Medicina. Inúmeros importantes cargos em órgãos ligados à Associação Médica Brasileira e à Sociedade Brasileira de Cardiologia. Foi Fundador e primeiro Presidente da Sociedade Brasileira de Pneumologia e Tisiologia, de 1978 a 1980, além de muitas outras atividades 
societárias nacionais e internacionais. Membro de Comissões Organizadoras e Presidente de conclaves médicos de caráter estadual e nacional em dezenas de vezes. Como se isso não bastasse, foi outras tantas campeão de remo, patrono do clube de remo Guaíba-Porto Alegre e rotariano ativo. A excelência de tamanha atividade foi recompensada com importantes prêmios e distinções médicas e comunitárias. Mas mais do que ressaltar a premiação cabe ressaltar o mérito, pois é sabido que existe muita premiação sem mérito e muito mérito sem premiação, principalmente para quem se mantém coerente dentro de um oficialismo geralmente hipócrita. $\mathrm{O}$ aqui exposto constitui parcela da parte visível de sua obra médica. Entretanto, além da rara inteligência, foram as qualidades intrínsecas de Mário Rigatto que explicam tamanha diversidade sem perder a excelência: capacidade de doação total, empenho para remover obstáculos, intransigência com princípios e amor como base da ação.

A capacidade de doação total a um ideal ficou claro já nos albores da carreira médica, quando decidiu dedicar-se em tempo integral ao ensino e à pesquisa. Essa foi a decisão fundamental que condicionou tantos resultados. O empenho para remover obstáculos foi outra característica sua, provindo da confiança e da coragem. Nada se faz sem coragem. Nos ensinou que lamentar não é o caminho e que quando falta a infra-estrutura se a constrói, se buscam recursos, se criam fontes de sustentação. Sempre soube atuar em todas as linhas de produção, desde a construção do pincel até o retoque do quadro! Deixa-nos também a lição tão necessária de que todos os mecanismos de ascensão buscados o sejam na base do respeito às regras e às pessoas, nunca cultivando o atropelamento, o curto-circuito ou o jeitinho. A desculpa tão usada de que é preciso pactuar com o sistema errado, para, nele ingressando, depois mudá-lo, jamais aceitou. Não conheço um só caso de transigência com a irregularidade que permitisse modificá-la. Ao contrário, com o tempo vem a desmoralização, enseja-se a barganha ilegítima, tudo continua no mesmo, apenas com mais um dúbio caráter auferindo vantagens. Ser honesto custa caro mas vale o preço.

Mas a qualidade por excelência de Mário Rigattoé o entusiasmo nascido do amor, que proíbe a mentira e o engodo. O amor é o maior dos sentimentos, o mandamento cristão por excelência, sem o qual ninguém triunfa verdadeiramente. Aprender, ensinar e pesquisar na sua trajetória transcendem os limites da ciência, completando-lhe as lacunas, e ao fazê-lo de maneira magistral transmutam-se em arte que convence, deleita e persuade. O mágico também pode ser exato e, como afirmam as palavras bíblicas, o amor tem que se traduzir em obras. Um homem menor só trabalha por interesse pessoal. Eé a ilegitimidade dos interesses que faz a escala da menoridade. $\mathrm{O}$ interesse aético acaba levando ao furto e ao servilismo. Chega a parecer que o aluguel da mídia é condição indispensável ao sucesso. Rigatto nunca transigiu com essas atitudes.

Apesar de toda a liderança nunca o vi temperamental ou prima-dona, estado tão comum nos pseudos gênios. Além do ensino e da pesquisa, o entusiasmo nascido do amor se direciona nele também para a comunidade, para a medicina da saúde e não da doença. A luta pela promoção do exercício físico e para livrar a sociedade da praga do tabagismo exemplificam muito bem esses aspectos. O justo alarde que se promove contra o risco da AIDS deveria ser multiplicado no mínimo por dez contra o tabagismo, mas interesses sujos o impedem. O número de vítimas do fumo é muito maior, como a mortalidade por essas situações pode chegar mais rápido que pela primeira.

Meu Mestre: Teus ensinamentos, por estarem muito além do status quo do meio, o deslumbravam quando proferidos em conferências mas, devido à distância entre ambos, talvez não tenham sido completamente absorvidos. Numa época de massificação e marcante uniformidade, o mundo precisa mais do que nunca de pessoas que não se limitem por padrões comuns e façam da originalidade e da criação não só uma conduta mas até um estilo de vida e, sendo cientistas, exaltem o entusiasmo pelas coisas, dando cor a verdade. Nossa sociedade, afundada no negativismo e tantas vezes frustrada, necessita urgentemente de referenciais positivos para lhe erguerem do catastrofismo e do opróbrio. Teu exemplo como referencial positivo é tua grande doação a todos nós.

As tuas imensas qualidades te permitiram, Mário Rigatto, que atravessasses a vida vestido de gala e borboleta, pronto para uma festa, sem deixar de ser simples e acessível, principalmente para com os que mais precisavam de ti, como os pobres e desvalidos; que fosses cortês e generoso, sem necessitar ser político; que tivesses sempre coragem, sem jamais ser arrogante; que fosses cientista laureado sem ficar limitado nas, às vezes, exíguas fronteiras da ciência.

As tuas ações nos teus 71 anos de vida extrapolam muito os limites de uma existência. Falavas em viver 120 anos. Por ironia do destino, não conseguiste, mas fizeste em 71 anos, nas várias vidas que tiveste, mais que um homem comum faria em 150 . Perdão, um homem comum não faria nunca tudo o que conseguiste fazer.

Meu querido Mário: não vou te dizer adeus, não vamos te dizer adeus, porque ficaremos com o mais precioso do teu legado: tua imagem, teus ensinamentos e teu exemplo.

Carlos A. M. Gottschall

Professor Pleno de Pós-Graduação em Cardiologia Titular da Academia Sul-Rio-Grandense de Medicina 